\title{
Neuromuscular blockade in the elderly patient
}

This article was published in the following Dove Press journal:

Journal of Pain Research

17 June 2016

Number of times this article has been viewed

\section{Luis A Lee \\ Vassilis Athanassoglou \\ Jaideep J Pandit \\ Nuffield Department of Anaesthetics, Oxford University Hospitals NHS \\ Foundation Trust, Oxford, UK}

Correspondence: Jaideep J Pandit

Nuffield Department of Anaesthetics,

Oxford University Hospitals NHS Trust,

Oxford OX3 9DU, UK

Tel +4401865222590

$\mathrm{Fax}+4401865220017$

Email jaideep.pandit@dpag.ox.ac.uk

\begin{abstract}
Neuromuscular blockade is a desirable or even essential component of general anesthesia for major surgical operations. As the population continues to age, and more operations are conducted in the elderly, due consideration must be given to neuromuscular blockade in these patients to avoid possible complications. This review considers the pharmacokinetics and pharmacodynamics of neuromuscular blockade that may be altered in the elderly. Compartment distribution, metabolism, and excretion of drugs may vary due to age-related changes in physiology, altering the duration of action with a need for reduced dosage (eg, aminosteroids). Other drugs (atracurium, cisatracurium) have more reliable duration of action and should perhaps be considered for use in the elderly. The range of interpatient variability that neuromuscular blocking drugs may exhibit is then considered and drugs with a narrower range, such as cisatracurium, may produce more predictable, and inherently safer, outcomes. Ultimately, appropriate neuromuscular monitoring should be used to guide the administration of muscle relaxants so that the risk of residual neuromuscular blockade postoperatively can be minimized. The reliability of various monitoring is considered. This paper concludes with a review of the various reversal agents, namely, anticholinesterase drugs and sugammadex, and the alterations in dosing of these that should be considered for the elderly patient.
\end{abstract}

Keywords: anesthesia, elderly, drugs, pharmacokinetics, pharmacodynamics

\section{Introduction}

Elderly patients are a continually growing population of health care consumers increasingly likely to need access to the highest quality health care. ${ }^{1}$ Quantifying this problem may be difficult, as the definitions of "elderly" have shifted from 65 to 75 years and beyond. The Working Party into the Perioperative Care of the Elderly 2014 even advocated for the abandonment of using chronological age to define "older." '2 Over time, the process of aging influences the cellular process, leading to the natural physiological decline of the cell's capability of division and function, finally leading to cell death. This results in $\sim 1 \%$ functional decline per year after 40 years of age. ${ }^{2}$

However, researchers rarely conduct large randomized controlled trials specifically in elderly patients and often exclude them from other trials. ${ }^{3}$ The reasons are multifactorial, but ultimately it is because elderly patients have multiple comorbidities and take many medicines, many of which cannot be stopped. These factors would introduce numerous confounding variables. As a result of the paucity of studies, predicting the action of drugs in the elderly can be difficult. ${ }^{4,5}$ 
In relation to anesthetic drugs, some things are known. The elderly population is more sensitive to neuromuscular blocking agents (NMBAs) due to alterations mainly in pharmacokinetics that occur with advancing age. Reduced volume of distribution ( $\mathrm{Vd}$ ) and clearance by age result in an increase in the concentration of drugs in blood. When hydrolysis by plasma cholinesterase is responsible for the elimination of muscle relaxants such as suxamethonium and mivacurium, an age-related decrease in this enzyme level causes a longer duration of action. ${ }^{6}$ The proper management of NMBAs in all patients (including the elderly) is important for several reasons. First, appropriate depth of the neuromuscular blockade is needed to facilitate surgery, in particular laparoscopic and open operations, ${ }^{7}$ as well as required in some forms of airway management, including both (temporarily) in mask ventilation and (sustained in) tracheal intubation. ${ }^{8}$ Second, residual neuromuscular blockade can lead to postoperative respiratory complications. ${ }^{9}$ Third, from the results of the Fifth National Audit Project in the UK (NAP5), NMBAs contribute to the genesis and impact of accidental awareness during general anesthesia: almost all $(97 \%)$ cases of possible awareness involved patients who received NMBAs. ${ }^{10-12}$ Finally, rapid reversal may be needed in the management of failed tracheal intubation. The largest audit of anesthetic activity in the UK recently confirmed that $\sim 46 \%$ of all general anesthetics involve the use of NMBAs. ${ }^{13}$

Age-related changes occur in all organs but the reduction is especially pronounced in the cardiovascular, respiratory, renal, hepatic, and central nervous system. ${ }^{14}$

\section{Pharmacology in the elderly Pharmacokinetics \\ Distribution}

Once a drug enters the bloodstream, it does not stay there. Rather it moves to different parts (compartments) of the body. The Vd of a drug is influenced by factors such as protein binding (only unbound drug can be distributed), $\mathrm{pH}$, molecular size, and solubility. The amount of drug present to produce an effect is proportional to its concentration at receptor sites. Therefore, the above changes in drug distribution can affect the response to the same drug doses. ${ }^{15}$ Lipid-soluble drugs have a higher $\mathrm{Vd}$ because they can cross the selective lipophilic cellular membrane. As people get older, lean body mass and total body water decrease, in contrast to body fat. Body fat can soak up fatsoluble drugs. ${ }^{15}$ Therefore, fat-soluble drugs will tend to have a higher $\mathrm{Vd}$ in elderly patients in contrast to younger patients. Conversely, water-soluble drugs and drugs mainly distributed in the extracellular fluid will have a lower $\mathrm{Vd} .^{5}$ In older people, smaller doses (by total body weight) of muscle relaxant are needed. ${ }^{5}$

Another change that occurs with aging is in protein binding. Distribution can occur only when the drug is unbound as big drug-protein complexes cannot cross the selective membranes. Plasma albumin concentration tends to decrease with age and structural protein changes that occur with age lead to decreased efficiency in albumin binding, to as little as $20 \%$ by the age of 70 years. ${ }^{16}$ Therefore, in the elderly, as less drug is protein bound, the free drug concentration will increase, enabling more drug to reach its receptors and thus have a pharmacologic effect. ${ }^{4,5}$

Plasma concentrations of NMBAs corresponding to a fixed degree of paralysis are not modified by aging and the concentration-response relationships remain usually unchanged, suggesting that aging does not influence the pharmacodynamic component of the NMBAs. ${ }^{17-19}$ Parker et $\mathrm{al}^{20}$ reported that the rate constant of exit from the effect compartment $\left(k_{e o}\right)$ decreases by 0.001 per minute per year, or $\sim 0.03$ per minute over three decades. Speculatively, this could be due to the effect of age on the peripheral circulation, leading to declining blood flow.

\section{Metabolism}

The liver is the primary organ responsible for drug metabolism. Liver mass decreases with age. Hepatic blood flow (HBF) decreases by $10 \%$ per decade. The capacity to metabolize drugs decreases. This decreased synthetic and metabolic activity as well as reduced $\mathrm{HBF}^{4,5}$ can alter the pharmacokinetic and pharmacodynamic properties of many drugs used during anesthesia, including NMBAs.

The aging process affects drug metabolism in three main ways. First, reduced HBF delivers the drug to the liver at a slower rate. Second, the decrease in liver mass influences hepatic function. Finally, the liver's intrinsic metabolic activity is also decreased. Therefore, as less drug reaches the liver per unit time and when it does less is metabolized due to the decrease in its metabolic activity, the duration of action of the drug will be increased. ${ }^{4,5}$ Increasing the percentage of unbound drug will have the same effect as more drug will be available to cause an effect. Foldes and Deery $^{21}$ calculated the protein-bound fraction of atracurium to be $\sim 82 \%$. With decreased hepatic function, less albumin is produced and thus protein binding of atracurium is decreased. When it decreased to $10 \%$, they found the amount of circulating free atracurium increased by $28 \%$, 
thus leading to an increase in the duration of action of a given dose. $^{21}$

However, the relative changes and contribution of the above effects are unknown and variable. In addition to the above factors, age, sex, genetics also play a major role in metabolic capacity. Therefore, it is practically impossible to quantify the extent of hepatic function reduction and accurately calculate the necessary drug dosage based on liver function tests. ${ }^{4,5}$

\section{Excretion}

Elimination of many drugs from the body occurs primarily via renal excretion. The half-life of drugs is increased as renal function is reduced. Renal function declines with age. Renal mass may decrease as much as $30 \%$ by the age of 80 , with the greatest reduction occurring in the renal cortex, corresponding with a decrease in the number of functioning glomeruli. The counter current gradients in the loop of Henle may be disrupted. Moreover, renal blood flow (RBF) decreases by $\sim 10 \%$ per decade due to a decrease in size of the renovascular bed. Regional RBF changes occur with decrease in cortical blood flow, whereas medullary blood flow is preserved. As $\mathrm{RBF}$ is reduced, glomerular filtration and concentrating ability decline linearly at $\sim 1 \%$ per year from 30 to 80 years. $^{14}$ Glomerular filtration rate and creatinine clearance decrease with age, but the serum creatinine level remains relatively unchanged because muscle bulk also decreases with age, resulting in less creatinine production. ${ }^{4,5}$

In contrast to the uncertainty surrounding hepatic influence on pharmacology, the influence of renal changes with age can be predicted with greater certainty. Dose adjustments can be guided by any changes in laboratory measurements (eg, glomerular filtration rate or serum creatinine).

\section{Effect site concentration}

Muscle blood flow has been suggested as a factor that influences delivery of drugs to the muscle end plate. Regional blood flows, including the muscle blood flow, are reduced in the elderly. Therefore, a more important concentration gradient between the effect site and the plasma in the elderly patients may exist, which is illustrated by a lower $k_{e o}$ in the elderly., 4,21 The slow onset and longer duration of action of most NMBAs in elderly patients, poorly explained by the modest changes in elimination kinetics, might correspond to this phenomenon.

\section{Pharmacodynamics}

Pharmacodynamics describes the effect a drug has on the body. All drugs affect the numerous organ systems in the body in different ways and cause variable adverse effects depending on their pharmacologic interactions. Aging causes some of these interactions to be more and others to be less pronounced.

In the context of this review, of particular concern is the stimulation of both muscarinic and nicotinic receptors by suxamethonium. Stimulation of cardiac muscarinic receptors in the sinoatrial node may lead to cardiac arrhythmias ranging from bradycardia to nodal rhythms and ventricular tachycardia. Muscle fasciculation and hyperkalemia may be exacerbated in elderly patients with renal failure, leading to intraoperative cardiac events. ${ }^{22}$ Abdominal muscle fasciculation and an increase in vagal tone may result in a suxamethonium-induced increase in intragastric pressure. ${ }^{23}$ However, risk of regurgitation and aspiration is negated by the simultaneous increase in lower esophageal pressure. ${ }^{23}$

Use of suxamethonium, particularly after use of anticholinesterase drugs, may result in a Phase II block, and this effect may be markedly prolonged in patients with chronic renal failure, ${ }^{24}$ which is more common in the elderly.

Nondepolarizing agents have their own complications. The use of benzylisoquinoliniums, such as atracurium, may result in histamine release, resulting in marked hypotension from tubocurarine and mivacurium. ${ }^{21}$ However, this does not appear to be clinically significant. ${ }^{25}$

Moreover, cisatracurium has very little, if any, cardiovascular effects, leading Cope and Hunter ${ }^{25}$ to suggest that it is the most suitable nondepolarizing NMBA for elderly patients.

\section{Pharmacology of NMBAs in the elderly Clinical findings \\ Onset time and duration of action}

The onset time of NMBAs is usually prolonged in the elderly irrespective of the drug used (vecuronium, rocuronium, suxamethonium, cisatracurium). ${ }^{26-30}$ Studies showing no difference in the onset time of neuromuscular blockade do exist; however, they used 2-3 times the ED95 as their initial dose. ${ }^{31}$ Koscielniak-Nielsen et $\mathrm{al}^{28}$ showed that, compared with younger patients, NMBAs in the elderly produce similar degree of neuromuscular blockade, but after a 2 minute delay.

\section{Depolarizing NMBAs}

\section{Suxamethonium}

The level of cholinesterase is decreased in the elderly. ${ }^{32}$ Frail elderly patients have lower plasma cholinesterase activity than fit older patients. ${ }^{6}$ Thus, less hydrolysis of suxamethonium 
resulting in longer duration of action is expected when it is administered to elderly patients.

\section{Nondepolarizing NMBAs}

Aminosteroids

Muscle relaxants with a steroid structure (pancuronium, vecuronium, rocuronium) are mainly eliminated by the liver through metabolism and biliary excretion, and partially excreted in the urine. They are poorly bound to plasma proteins. These large molecules are highly ionized regardless of $\mathrm{pH}$, which limits their distribution to the extracellular compartment. As a consequence, their $\mathrm{Vd}$ remains unchanged or slightly decreases with aging.

Pharmacokinetic parameters for steroid NMBAs are modified by aging, with a trend toward reduction in both clearance $(\sim 30 \%)$ and distribution volumes $(\sim 25 \%)$, causing less redistribution of the drugs out of the central compartment. These are the main mechanisms leading to a prolongation of action of aminosteroid NMBAs. ${ }^{33,34}$

Vecuronium is scarcely metabolized, with $40 \%$ excreted unchanged in the bile and $30 \%$ in the urine. A limited amount of the drug is deacetylated in the liver with one active metabolite. As both $\mathrm{HBF}$ and glomerular filtration rate are reduced with age, vecuronium clearance is decreased by $\sim 30 \%$ in this population, without any modification in the $\mathrm{Vd}$. This is probably the main mechanism for the prolongation of duration of action and recovery intervals (up to $30 \%$ longer) in elderly patients. ${ }^{33,35,36}$ Simply titrating dose to effect, rather than giving a fixed dose, may avoid this prolongation of recovery time.

Rocuronium is eliminated in a similar manner to vecuronium. Approximately $75 \%$ is eliminated in the bile and $10 \%$ in the urine. A little rocuronium undergoes deacetylation, and no significantly active metabolites are produced. Clearance of rocuronium decreases with age, almost by $30 \%$ when compared with adults in their 40s. ${ }^{29}$ This explains its prolongation of action after a bolus for intubation or maintenance. After a bolus dose for intubation or maintenance, its action is prolonged. ${ }^{29}$ This prolongation may be as much as a twofold increase, from 31 minutes in younger patients to 51 minutes in the elderly. ${ }^{37}$ Therefore, in elderly patients, extra doses should be administered with care, only after the reappearance of train-of-four response.

Clinical effects of some neuromuscular blockers are occasionally not readily explained by pharmocokinetic changes. Doxacurium exhibits a prolonged duration of action similar to other NMBAs despite its clearance and elimination halflife not appearing to alter with age. ${ }^{38}$ Conversely, despite reduced clearance of pipecuronium in renal failure, ${ }^{39}$ there appears to be no clinical reduction in the duration of action in the elderly. ${ }^{40}$

\section{Benzylisoquinoliniums}

The currently available benzylisoquinoliniums include atracurium, mivacurium, and cisatracurium. Atracurium and mivacurium are mixtures of stereoisomers with varying potencies and pharmacokinetic properties. Atracurium is a mixture of ten isomers, one of them being cisatracurium.

Like steroid NMBAs, benzylisoquinoliniums are big molecules that do not cross lipid membranes. They are more protein bound than steroid compounds and due to less protein binding in the elderly, their $\mathrm{Vd}$ is slightly increased.

Atracurium and cisatracurium are eliminated from the body by Hofmann degradation, a process that is temperature and $\mathrm{pH}$-dependent. Therefore, compared with steroidal NMBAs, they depend less on renal and hepatic function for their elimination.

Metabolism or hydrolysis of benzylisoquinolinium compounds is diverse. Atracurium and cisatracurium mainly undergo spontaneous degradation not only through Hofmann degradation but also secondarily ester hydrolysis. This process accounts for $\sim 83 \%$ of cisatracurium elimination but only for $\sim 40 \%$ of atracurium total clearance..$^{30}$ The fraction of atracurium that does not undergo Hofmann elimination is mainly metabolized in the liver and eliminated renally. Renal elimination of atracurium ranges from $10 \%$ to $50 \%$, whereas for cisatracurium is $\sim 16 \%{ }^{41}$

The pharmacokinetics of atracurium and cisatracurium are altered in the elderly. Parker et $\mathrm{al}^{42}$ in 1992 showed that with increasing age, clearance decreases and elimination half-life increases. Specifically, in the case of atracurium, the half-life is increased by $15 \%{ }^{43,44}$ However, these pharmacokinetic changes are not translated to clinically significant effects. ${ }^{43,45}$ In elderly patients, recovery from both induction and maintenance bolus of cisatracurium is increased. ${ }^{30,46}$

Elderly patients are more sensitive to atracurium doses, the reason for which remains unclear. ${ }^{47}$ Xue et $\mathrm{al}^{47}$ showed the above to be true, as smaller doses were needed to produce the same clinical result and the duration of action of a given dose was increased. A proposed mechanism was the increased sensitivity of the neuromuscular junction. However, this might not be the answer as d'Hollander et $\mathrm{al}^{35}$ found that both in the elderly and the younger patients, the same dose of atracurium was needed to suppress the twitch response by $50 \%$. 
Another benzylisoquinolinium, mivacurium, a short-acting NMBA, showed prolongation of recovery and increased onset time. ${ }^{27,48}$ It is almost exclusively eliminated through hydrolysis by plasma cholinesterases,${ }^{31}$ the activity of which decreases in the elderly. ${ }^{27}$ Its clearance and elimination halflife in the elderly are thought to be unchanged ${ }^{48}$ In clinical practice, Dahaba et al ${ }^{49}$ suggested a reduction of infusion dose from 0.5 to $0.4 \mathrm{mg} / \mathrm{kg} / \mathrm{h}$ after a standard initial dose of $0.15 \mathrm{mg} / \mathrm{kg}$.

Sagir et a ${ }^{50}$ directly compared rocuronium, vecuronium, and cisatracurium in elderly patients undergoing abdominal surgery. They concluded that the benzylisoquinolinium compound was safer than the two aminosteroids in the elderly because it performed better in time to positive strength and visual disturbance tests, indicating less risk of residual neuromuscular blockade. ${ }^{50}$

\section{Interpatient variability of recovery}

Interpatient variability in neuromuscular blockade is more pronounced in the elderly population. Duration of actions of various neuromuscular blockers ranges from cisatracurium (37-81 minutes), vecuronium (35-137 minutes), and rocuronium (33-119 minutes).$^{51}$ Cisatracurium has the smallest median variability of duration ( 7 minutes) compared with vecuronium and rocuronium (18 minutes each).${ }^{51}$ This suggests greater reliability in using cisatracurium for elderly patients..$^{52}$

A possible reason for the interpatient variability may be the usage of actual body weight in estimating dosages of NMBAs. Variations in body habitus and composition of the body of the elderly may result in an overdosing due to the altered pharmacokinetics of NMBAs caused by, as previously mentioned, increased fat, decreased muscle mass, and lower $\mathrm{Vd}^{37}$

With suxamethonium, the decrease in the level of plasma cholinesterase would result in a more prolonged duration of action. This level of plasma cholinesterase may also depend on the physical fitness of the elderly patient, with frail elderly patients having more impaired enzyme activity.

Steroid neuromuscular blockers appear to have a greater degree of variability as they are dependent on organ elimination. Furuya et $\mathrm{al}^{37}$ showed that the time of appearance of the first post-tetanic count was both increased and more variable in patients over 70 years compared with younger patients.

Furthermore, it appears that the usage of volatile anesthesia may produce increased variability in the duration of action of steroidal NMBAs compared with cisatracurium in the elderly. A comparison of Furuya et al's ${ }^{37}$ study using sevoflurane with Baykara's study using propofol and opioid showed an increase of 19 minutes with sevoflurane. ${ }^{53}$ This increase is thought to be due to sevoflurane pharmacodynamically potentiating the neuromuscular blocker as well as the volatile anesthetic, limiting peripheral blood flow to the muscles. ${ }^{37}$

\section{Use of neuromuscular blockade monitoring in the elderly}

The increased duration of action and decreased clearance of most NMBAs may predispose geriatric patients to inadequate recovery from neuromuscular blockade. Advanced age is a risk factor for residual neuromuscular block and resulting respiratory complications. ${ }^{9}$ Because of the above, it is even more important in elderly patients to monitor the effects of the NMBAs both in determining the frequency and dosage of repeated administration of these agents and the appropriate administration of reversals.

Quantitative monitors for monitoring residual blockage are not commonplace, with an estimated $10 \%$ of anesthetists using them routinely. ${ }^{25,54}$ There is also no unanimous means of confirming complete recovery from neuromuscular blockade. $^{25,54}$

There are different modes of nerve stimulation (eg, single twitch, double-burst stimulation, train-of-four stimulation, and tetanic stimulation and posttetanic count) and although commonly used, visual assessment can be inaccurate as a means of monitoring depth of neuromuscular blockade, mechanical or electrical methods being preferable. Mechanomyography, frequently using the adductor pollicis of the thumb, may be cumbersome and is perhaps better viewed as a research tool; it is generally impractical for use in the operating theatre. ${ }^{55}$ Electromyography (recording the compound action potential generated by the muscle contraction) and acceleromyography (measuring acceleration rather than force of contraction) are both electrical methods that are less bulky. Kinemyography also shows promise, using piezoelectric crystals as motion sensors. ${ }^{56}$

Of the various tests available, the train-of-four (TOF) stimulation appears to be the most commonly used, and some papers advocate a TOF $>0.9$ as sufficient recovery of neuromuscular blockade to avoid related postoperative complications. ${ }^{57-59}$ However, other studies suggested that even a TOF $>0.9$ shows insufficient recovery of neuromuscular blockade. ${ }^{60,61}$ Therefore, it is recommended that a combination of TOF assessment together with clinical tests (eg, sustained head lift or grip strength) should be used for the assessment of neuromuscular recovery. ${ }^{50}$ 


\section{Neuromuscular blockade reversal in the elderly}

A recent study by Murphy et $a{ }^{62}$ suggested that postoperative residual neuromuscular blockade may be twice as common in the elderly (incidence of 57\%) as in the younger population (30\%), leading to increased postanesthesia care unit and hospital stay as well as a higher incidence of hypoxemic events, airway obstruction, and other symptoms of muscle weakness. This illustrates the need for accurate dosage of NMBAs, vigilant monitoring of their effects, and if necessary, appropriate administration of reversal agents.

Reversal of neuromuscular blockade, if required, tends to be with anticholinesterase drugs. Neostigmine, pyridostigmine, and edrophonium are all acetylcholinesterase inhibitors but have different uses.

Neostigmine is the most common anticholinesterase drug used, antagonizing the effects of neuromuscular blockers by carbamylation of their esterase sites. Neostigmine's Vd is increased in the elderly as it is a polar molecule that is not very lipid soluble and, as previously mentioned, the body's fat content increases compared to muscle, resulting in a more prolonged duration of action. ${ }^{63}$ Similar to neostigmine, pyridostigmine's action is prolonged in the elderly due to decreased renal function leading to decreased plasma clearance. ${ }^{64}$ In contrast, the duration of action of edrophonium remains unchanged. Therefore, neostigmine and pyridostigmine are preferable to edrophonium as NMBA reversal agents as their prolonged duration of action can negate the prolonged duration of action of NMBAs that occur with advancing age. ${ }^{63}$

Sugammadex, a modified g-cyclodextrin, reverses the neuromuscular blockade of aminosteroidal agents, such as rocuronium and vecuronium, by binding and forming a complex, which is primarily excreted by the kidneys. Therefore, a reduction in kidney function would lead to decrease in clearance and extension of its half-life and duration of action.$^{65}$ In patients older than 75 years, a reduction of clearance to $50 \%$ would result in a near doubling of the effective half-life of sugammadex. ${ }^{65}$ Reversal lasts significantly longer in elderly patients. ${ }^{60}$ Suzuki et al ${ }^{66}$ speculated that this was due to, first, decreased cardiac output and, second, decreased muscle blood flow. Another group quantified the increase in duration by finding that neuromuscular blockade lasted 0.7 minutes more in the elderly patients compared with younger adults. ${ }^{65}$ This finding was confirmed by Kadoi et al, ${ }^{67}$ who found significant differences in both recovery of TOF ratio to $>0.9$ and time to first spontaneous breath between the younger ( $<50$ years) group (403 s) and the elderly (>70 years) group (443 s). Of note are the recommendations from the manufacturers of sugammadex that, although the recovery time tends to be slower, the same dose recommendation as for younger adults should be followed to minimize the risk of any residual neuromuscular blockade. ${ }^{68}$

\section{Conclusion}

This article provides a review for anesthetists to consider modifications in the administration of neuromuscular blockers for the elderly patient undergoing general anesthesia. Although the main focus has been on age-related changes, it is stressed that by virtue of aging, other factors also come into play, notably cardiovascular or renal and hepatic disease, which independently influence the distribution and handling of drugs. Furthermore, there is increasing recognition of obesity in the aging population, which in turn can influence drug disposition..$^{69,70}$ There must be careful deliberation of pharmacokinetic and pharmacodynamic principles on an individual case basis to avoid unintentional prolonged duration of action. Consideration of appropriate agents and the usage of neuromuscular blockade monitoring as well as the judicious use of NMBA reversal agents would decrease the risk of residual blockade and postoperative complications.

\section{Disclosure}

The authors report no conflicts of interest in this work.

\section{References}

1. Bressler R, Bahl JJ. Principles of drug therapy for the elderly patient. Mayo Clin Proc. 2003;78:1564-1577.

2. Griffiths R, Beech F, Brown A, et al. Perioperative care of the elderly 2014: Association of Anaesthetists of Great Britain and Ireland. Anaesthesia. 2014;69(Suppl.1):81-98.

3. Le Quintrec J-L, Bussy C, Golmard J-L, Herve C, Baulon A, Piette F. Randomised controlled drug trials on very elderly subjects: Descriptive and methodological analysis of trials published between 1990 and 2002 and comparison with trials on adults. J Gerontol Biol Sci Med Sci. 2005;60:340-344.

4. Hutchison LC, O'Brien CE. Changes in pharmacokinetics and pharmacodynamics in the elderly patient. J Pharm Pract. 2007;20:4-12.

5. Mangoni AA, Jackson SH. Age-related changes in pharmacokinetics and pharmacodynamics: basic principles and practical applications. $\mathrm{Br}$ J Clin Pharmacol. 2004;57:6-14.

6. Hubbard RE, O’Mahony MS, Calver BL, Woodhouse KW. Plasma esterases and inflammation in ageing and frailty. Eur J Clin Pharmacol. 2008;64:895-900.

7. Madsen MV, Staehr-Rye AK, Gätke MR, Claudius C. Neuromuscular blockade for optimizing surgical conditions during abdominal and gynaecological surgery: a systematic review. Acta Anaesthesiol Scand. 2015;59:1-16.

8. Frerk C, Mitchell VS, McNarry AF, et al. Difficult Airway Society 2015 guidelines for management of unanticipated difficult intubation in adults. Br J Anaesth. 2015;115:827-848. 
9. Berg H, Roed J, Viby-Mogensen J, et al. Residual neuromuscular block is a risk factor for postoperative pulmonary complications. A prospective, randomised, and blinded study of postoperative pulmonary complications after atracurium, vecuronium and pancuronium. Acta Anaesthesiol Scand. 1997;41:1095-1103.

10. Pandit JJ, Andrade J, Bogod DG, et al; Royal College of Anaesthetists and the Association of Anaesthetists of Great Britain and Ireland. The 5th National Audit Project (NAP5) on accidental awareness during general anaesthesia: protocol, methods and analysis of data._Anaesthesia 2014;69:1078-1088.

11. Pandit JJ, Andrade J, Bogod DG, et al; Royal College of Anaesthetists and the Association of Anaesthetists of Great Britain and Ireland. The 5th National Audit Project (NAP5) on accidental awareness during general anaesthesia: summary of main findings and risk factors. $\mathrm{Br} J$ Anaesth. 2014;69:1089-1101.

12. Cook TM, Andrade J, Bogod DG, et al. The 5th National Audit Project (NAP5) on accidental awareness during general anaesthesia: patient experiences, human factors, sedation, consent and medicolegal issues Br J Anaesth. 2014;69:1102-1116.

13. Sury MR, Palmer JH, Cook TM, Pandit JJ. The state of UK anaesthesia: a survey of National Health Service activity in 2013. Br J Anaesth. 2014;113:575-584.

14. Muravchick S. Preoperative assessment of the elderly patient. Anesthesiol Clin North America. 2000;18:71-89.

15. Plein J, Plein E. Pharmacokinetics and pharmacodynamics in the geriatric patients. In: Krechel SW, editor. Anesthesia and the Geriatric Patient. London: Grune \& Stratton, Inc; 1984:73-98.

16. Richey DP, Bender AD. Pharmacokinetic consequences of aging. Annu Rev Pharmacol Toxicol. 1979;17:49-65

17. Duvaldestin P, Saada J, Berger JL, d'Hollander A, Desmonts JM. Pharmacokinetics, pharmacodynamics, and dose-response relationships of pancuronium in control and elderly subjects. Anesthesiology. 1982;56:36-40.

18. Matteo RS, Backus WW, McDaniel DD, Brotherton WP, Abraham R, Diaz J. Pharmacokinetics and pharmacodynamics of d-tubocurarine and metocurine in the elderly. Anesth Analg. 1985;64:23-29.

19. Rupp SM, Castagnoli KP, Fisher DM, Miller RD. Pancuronium and vecuronium pharmacokinetics and pharmacodynamics in younger and elderly adults. Anesthesiology. 1987;67:45-49.

20. Parker CJ, Hunter JM, Snowdon SL. Effects of age, gender and anesthetic technique on the pharmacodynamics of atracurium. Br J Anesth. 1993;70:38-41.

21. Foldes FF, Deery A. Protein binding of atracurium and other shortacting neuromuscular blocking agents and their interaction with human cholinesterases. Br J Anaesth. 1983;55:31S-34S.

22. Huggins, RM, Kennedy WK, Melroy MJ, Tollerton DG. Cardiac arrest from succinylcholine-induced hyperkalemia. Am J Health Syst Pharm. 2003;60:694-697.

23. Appiah-Ankam J, Hunter JM. Pharmacology of neuromuscular blocking drugs. Contin Educ Anaesth Crit Care Pain. 2004;4:2-7.

24. Williams AR, Bailey M, Joye T, Burt N. Marked prolongation of the succinylcholine effect two hours after neostigmine reversal of neuromuscular blockade in a patient with chronic renal insufficiency. South Med J. 1999;92:77-79.

25. Cope TM, Hunter JM. Selecting neuromuscular-blocking drugs for elderly patients. Drugs Aging. 2003;20:125-140.

26. Goat VA, Yeung ML, Blakeney C, Feldman SA. The effect of blood flow upon the activity of gallamine triethiodide. Br J Anaesth. 1976;48:69-73.

27. Maddineni VR, Mirakhur RK, McCoy EP. Plasma cholinesterase activity in elderly and young adults. Br J Anaesth. 1994;72:497.

28. Koscielniak-Nielsen ZJ, Bevan JC, Popovic V, Baxter MR, Donati F, Bevan DR. Onset of maximum neuromuscular block following succinylcholine or vecuronium in four age groups. Anesthesiology. 1993;79:229-234.

29. Matteo RS, Ornstein E, Schwartz AE, Ostapkovich N, Stone JG. Pharmacokinetics and pharmacodynamics of rocuronium (Org 9426) in elderly surgical patients. Anesth Analg. 1993;77:1193-1197.
30. Sorooshian SS, Stafford MA, Eastwood NB, Boyd AH, Hull CJ, Wright PM. Pharmacokinetics and pharmacodynamics of cisatracurium in young and elderly adult patients. Anesthesiology. 1996;84:1083-1091.

31. Belmont MR, Lien CA, Tjan J, et al. Clinical pharmacology of GW280430A in humans. Anesthesiology. 2004;100:768-773.

32. Chan L. Blood cholinesterase levels in the elderly and newborn. Malays J Pathol. 1995;17:87-89.

33. Lien CA, Matteo RS, Ornstein E, Schwartz AE, Diaz J. Distribution, elimination, and action of vecuronium in the elderly. Anesth Analg. 1991;73:39-42.

34. Wright PM, Hart P, Lau M, Sharma ML, Gruenke L, Fisher DM. Cumulative characteristics of atracurium and vecuronium. A simultaneous clinical and pharmacokinetic study. Anesthesiology. 1994;81:59-68.

35. d'Hollander AA, Massaux F, Nevelsteen M, Agoston S. Age dependent dose-response relationship of Org NC45 in anaesthetized patients. $\mathrm{Br}$ J Anaesth. 1982;54:653-657.

36. McCarthy G, Elliott P, Mirakhur RK, Cooper R, Sharpe TD, Clarke RS. Onset and duration of action of vecuronium in the elderly: comparison with adults. Acta Anaesthesiol Scand. 1992;36:383-386.

37. Furuya T, Suzuki T, Kashiwai A, et al. The effects of age on maintenance of intense neuromuscular block with rocuronium. Acta Anaesthesiol Scand. 2012;56:236-239.

38. Dresner DL, Basta SJ, Ali HH, et al. Pharmacokinetics and pharmacodynamics of doxacurium in young and elderly patients during isoflurane anesthesia. Anesth Analg. 1990;71:498-502.

39. Cadwell JE, Canfell PC, Castagnoli KP, et al. The influence of renal failure on the pharmacokinetics and duration of action of pipecuronium bromide in patients anesthetized with halothane and nitrous oxide. Anesthesiology. 1989;70:7-12.

40. Ornstein E, Matteo RS, Schwartz AE, Jamdar SC, Diaz J. Pharmacokinetics and pharmacodynamics of pipecuronium bromide (Arduan) in elderly surgical patients. Anesth Analg. 1992;74:841-844.

41. Kisor DF, Schmith VD, Wargin WA, Lien CA, Ornstein E, Cook DR. Importance of the organ-independent elimination of cisatracurium Anesth Analg. 1996;83:1065-1071.

42. Parker CJ, Hunter JM, Snowdon SL. Effects of age, sex and anesthetic technique on the pharmacokinetics of atracurium. BrJ Anesth. 1992;69:439-443.

43. Kitts JB, Fisher DM, Canfell PC, et al. Pharmacokinetics and pharmacodynamics of atracurium in the elderly. Anesthesiology. 1990;72:272-275.

44. Kent AP, Parker CJ, Hunter JM. Pharmacokinetics of atracurium and laudanosine in the elderly. Br J Anaesth. 1989;63:661-666.

45. d'Hollander AA, Luyckx C, Barvais L, De Ville A. Clinical evaluation of atracurium besylate requirement for a stable muscle relaxation during surgery: lack of age-related effects. Anesthesiology. 1983;59: $237-240$.

46. Ornstein E, Lien CA, Matteo RS, Ostapkovich ND, Diaz J, Wolf KB. Pharmacodynamics and pharmacokinetics of cisatracurium in geriatric surgical patients. Anesthesiology. 1996;84:520-525.

47. Xue FS, Zhang YM, Liao X, Liu JH, An G. Influences of age and gender on dose response and time course of effect of atracurium in anesthetized adult patients. J Clin Anesth. 1999;11:397-405.

48. ØStergaard D, Viby-Mogensen J, Pedersen NA, Holm H, Skovgaard LT. Pharmacokinetics and pharmacodynamics of mivacurium in young adult and elderly patients. Acta Anaesthesiol Scand. 2002;46: 684-691.

49. Dahaba AA, Rehak PH, List WF. A comparison of mivacurium infusion requirements between young and elderly adult patients. Eur $J$ Anaesthesiol. 1996; 13(1):43-48.

50. Sagir O, Yucesoy Noyan F, Koroglu A, Cicek M, IIksen Toprak H. Comparison between the effects of rocuronium, vecuronium, and cisatracurium using train-of-four and clinical tests in elderly patients. Anesth Pain Med. 2013;2:142-148.

51. Arain Sr, Kern S, Ficke DJ, Ebert TJ. Variability of duration of action of neuromuscular blocking drugs in elderly patients. Acta Anaesthesiol Scand. 2005;49:312-315. 
52. Puhringer FK, Heier T, Dodgson M, et al. Double-blind comparison of the variability in spontaneous recovery of cisatracurium- and vecuronium-induced neuromuscular block in adult and elderly patients. Acta Anaesthesiol Scand. 2002;46:364-371.

53. Baykara N, Sahin T, Alpar R, Solak M, Toker K. Evaluation of intense neuromuscular blockade caused by rocuronium using posttetanic count in male and female patients. J Clin Anesth. 2003; 15:446-50.

54. Grayling M, Sweeney BP. Recovery from neuromuscular blockade: a survey of practice. Anaesthesia. 2007;62:806-809.

55. McGrath CD, Hunter JM. Monitoring of neuromuscular block. Contin Educ Anaesth Crit Care Pain. 2006;6:7-12.

56. Dahaba AA, Von Klobucar F, Rehak PH, List WF. Comparison of a new piezoelectric train-of-four neuromuscular monitor, the ParaGraph, and the Relaxometer mechanomyograph. Br J Anaesth. 1999;82:780-782.

57. Ali HH. Criteria of adequate clinical recovery from neuromuscular block. Anesthesiology. 2003;98:1278-1280.

58. Capron F, Alla F, Hottier C, Meistelman C, Fuchs-Buder T. Can acceleromyography detect low levels of residual paralysis? A probability approach to detect a mechanomyographic train-of-four ration of 0.9 . Anesthesiology. 2004;100:1119-1124.

59. Hemmerling TM, Le N. Brief review: Neuromuscular monitoring: an update for the clinician. Can J Anaesth. 2007;54:58-72.

60. Naguib M, Kopman AF, Ensor JE. Neuromuscular monitoring and postoperative residual curarisation: a meta-analysis. Br J Anaesth. 2007;98:302-316.

61. Balliard C, Gehan G, Reboul-Marty J, et al. Residual curarization in the recovery room after vecuronium. Br J Anaesth. 2000;84:394-395.

62. Murphy GS, Szokol JW, Avram MJ, et al. Residual neuromuscular block in the elderly: incidence and clinical implications. Anesthesiology. 2015; 123:1322-1336.
63. Young WL, Matteo RS, Ornstein E. Duration of action of neostigmine and pyridostigmine in the elderly. Anesth Analg. 1988;67:775-778.

64. Stone JG, Matteo RS, Ornstein E, et al. Aging alters the pharmacokinetics of pyridostigmine. Anesth Analg. 1995;8:773-776.

65. McDonagh DL, Benedict PE, Kovac AL, et al. Efficacy, safety and pharmacokinetics of sugammadex for the reversal of rocuroniuminduced neuromuscular blockade in elderly patients. Anesthesiology. 2011;114:318-329.

66. Suzuki T, Kitajima O, Ueda K, Kondo Y, Kato J, Ogawa S. Reversibility of rocuronium-induced profound neuromuscular block with sugammadex in younger and older patients. Br J Anaesth. 2011;106: 823-826.

67. Kadoi Y, Nishida A, Saito S. Recovery time after sugammadex reversal of rocuronium-induced muscle relaxation for electroconvulsive therapy is independent of cardiac output in both young and elderly patients. $J$ ECT. 2013;29:33-36.

68. European Medicines Agency. Bridion: Summary of Product Characteristics [online]. Available from: http://www.ema.europa.eu/docs/en_GB/ document_library/EPAR_-_Product_Information/human/000885/ WC500052310.pdf. Accessed October 9, 2015.

69. Villareal DT, Apovian CM, Kushner RF, Klein S; American Society for Nutrition; NAASO, The Obesity Society. Obesity in older adults: technical review and position statement of the American Society for Nutrition and NAASO, The Obesity Society. American Society for Nutrition; NAASO, The Obesity Society. Am J Clin Nutr. 2005;82: 923-934.

70. Nightingale CE, Margarson MP, Shearer E, et al. Perioperative management of the obese surgical patient 2015: Association of Anaesthetists of Great Britain and Ireland Society for Obesity and Bariatric Anaesthesia. Anaesthesia. 2015;70:859-76.
Journal of Pain Research

\section{Publish your work in this journal}

The Journal of Pain Research is an international, peer reviewed, open access, online journal that welcomes laboratory and clinical findings in the fields of pain research and the prevention and management of pain. Original research, reviews, symposium reports, hypothesis formation and commentaries are all considered for publication.

\section{Dovepress}

The manuscript management system is completely online and includes a very quick and fair peer-review system, which is all easy to use. Visit http://www.dovepress.com/testimonials.php to read real quotes from published authors. 